\title{
Sirtuin 1 Expression and Correlation with Histopathological Features in Retinoblastoma
}

\author{
Atul Batra ${ }^{a, c, d}$ Seema Kashyap ${ }^{b, d} \quad$ Lata Singh $^{\text {b, d } \quad \text { Sameer Bakhshi }}{ }^{a, c, d}$ \\ Departments of ${ }^{a}$ Medical Oncology and ${ }^{b}$ Ocular Pathology, and ${ }^{c}$ Dr. B.R.A. Institute Rotary Cancer Hospital, \\ ${ }^{\mathrm{d}}$ All India Institute of Medical Sciences, New Delhi, India
}

\section{Key Words}

Sirtuin $1 \cdot$ Retinoblastoma $\cdot$ Histopathology

\begin{abstract}
Background: Sirtuin1 (Sirt1) is a member of highly conserved proteins and has been implicated as a tumor promoter as well as a tumor suppressor. One of the mechanisms involves deacetylation of retinoblastoma protein, thereby inhibiting the tumor suppressor function. No study has been reported on the expression of Sirt1 in retinoblastoma. Methods: We assessed the expression of Sirt1 in sections of archived tissue blocks of enucleated and exenterated specimens of retinoblastoma patients by immunohistochemistry. The histopathological features were reviewed and correlated with the expression of Sirt1. The effect of Sirt 1 expression on survival was also assessed. Results: Retrospective data of 94 patients revealed that the median age at presentation was 36 months, with a male:female ratio of 1.9:1. Fifty-one percent of the patients had International Retinoblastoma Staging System (IRSS) stage 1 disease. Of the 94 sections, 89 (95\%) expressed Sirt1. Forty-eight percent of the specimens showed grade 3 staining ( $>75 \%$ of the cells), and the intensity was $3+$ in $53 \%$. No association between Sirt1 expression and any histopathological feature was noted. Further, Sirt 1 expression did not affect the overall and progression-free
\end{abstract}

survival. Conclusions: Sirt1 was expressed in most of the retinoblastoma samples. However, the degree of Sirt1 expression was not associated with any high-risk histopathological feature or survival.

(c) 2015 S. Karger AG, Basel

\section{Introduction}

The name 'sirtuin' has been derived from Sir2, the yeast gene 'silent mating type information regulation 2 homolog' responsible for cellular regulation in yeast. Seven sirtuins have been identified in mammals (Sirt1-7), with distinct subcellular localizations and functions [1]. Sirt1 is located in the nucleus, whereas the other sirtuins are located in mitochondria, nucleolus and cytoplasm. The mechanism of action of sirtuins involves their nicotinamide dinucleotide-dependent mono-ribosyltransferase or deacylase activity and a host of substrates including p53 and forkhead box protein O. Sirtuins have been implicated as both tumor suppressor as well as tumor promoter genes [2-5]. Sirt1 has been the most studied sirtuin in carcinogenesis. Sirt1 deacetylates p53 at lysine 382, thereby reducing its transactivation and hence acting as apoptotic factor. However, Sirt1 also plays a key role in the DNA break repair, supporting its tumor suppressor role.

\section{KARGER}

E-Mail karger@karger.com

www.karger.com/oop
(C) 2015 S. Karger AG, Base

2296-4681/15/0022-0086\$39.50/0
Dr. Sameer Bakhshi

Department of Medical Oncology, Dr. B.R.A. Institute Rotary Cancer Hospital All India Institute of Medical Sciences

Room No. 243, Second Floor, Ansari Nagar, New Delhi 110029 (India)

E-Mailsambakh@hotmail.com 
Retinoblastoma protein functions to regulate the G1/S transition of the cell cycle through its interaction with the E2F family of transcription factors [6]. The activity of retinoblastoma protein is regulated predominantly by phosphorylation and dephosphorylation. However, deacetylation of appropriate lysine residues is also known to deactivate the protein [7]. Sirt1 has been reported to bind to the pocket domain of the retinoblastoma protein and to cause its deacetylation, which is nicotinamide dinucleotide-dependent [8].

Since a functional interaction exists between retinoblastoma protein and Sirt1, the latter may be involved in the pathogenesis of retinoblastoma. Overexpression or gain of the function mutation of Sirt1 may lead to the functional loss of retinoblastoma protein and thus to carcinogenesis.

Moreover, Sirt1 inhibitors (Sirtinol, Tenovin-1 and Ex527) have shown preclinical activity in breast cancer and melanoma by targeting the $\mathrm{p} 53$ and PI3K pathway $[9,10]$. This class of drugs may provide an effective novel therapy in retinoblastoma if Sirt1 is involved in the pathogenesis.

Based on this hypothesis, we studied the expression of Sirtl in the archived tissue blocks of enucleated and exenterated specimens of retinoblastoma patients.

\section{Materials and Methods}

\section{Study Design}

This was a retrospective study conducted at the All India Institute of Medical Sciences, New Delhi, India. The archived tissue blocks of treated retinoblastoma patients were retrieved. The demographic, clinical and survival data of these patients were retrieved from the database at our center. The diagnosis was confirmed by a histopathology review. The review of histopathological features including differentiation, necrosis, calcification, involvement of the optic nerve and its cut end, choroid and other ocular structures was done. The institutional ethics committee approved the study.

\section{Treatment}

In patients with IRSS stage I disease, 6 cycles of postenucleation chemotherapy were given as chemoprophylaxis if any high-risk factor was identified in histopathology (invasion of the anterior chamber, iris, ciliary body, sclera, postlaminar optic nerve or massive choroidal invasion); in IRSS stage II disease, 12 cycles of adjuvant chemotherapy along with radiotherapy were administered following enucleation [11]. Stage III tumors were managed with 3 cycles of neoadjuvant chemotherapy followed by enucleation or exentration, radiotherapy and adjuvant chemotherapy (total 12 cycles) [12]. Metastatic retinoblastoma patients were managed by chemotherapy followed by high-dose chemotherapy with autologous stem cell transplantation in those who had limited metastasis and showed very good response to chemotherapy. The chemo- therapeutical agents included a combination of vincristine (1.5 $\mathrm{mg} / \mathrm{m}^{2}$ ), etoposide $\left(150 \mathrm{mg} / \mathrm{m}^{2}\right.$ for 2 days) and carboplatin (560 $\mathrm{mg} / \mathrm{m}^{2}$ ) administered at 4 -week intervals.

\section{Immunohistochemistry}

The immunohistochemical detection of Sirt1 protein was performed on formalin-fixed, paraffin-embedded sections $(5 \mu \mathrm{m}$ thick) using rabbit polyclonal Sirt 1 antibody (Pierce, Thermo Fisher Scientific, Rockford, Ill., USA). The sections were deparaffinized and rehydrated in ethanol. Antigen retrieval was performed by a heat-based method, i.e. the microwave oven method, in $0.01 \mathrm{~mol} / \mathrm{l}$ sodium citrate buffer ( $\mathrm{pH}$ 6.0). Then, the slides were allowed to cool down for additional $5 \mathrm{~min}$ in the same buffer. After repeated rinses in tris-buffered saline, the slides were pretreated with hydrogen peroxidase blocking reagent (Thermoquanto) for $5 \mathrm{~min}$. Sirt1 polyclonal antibody (dilution 1:100) was used as the primary antibody for $1 \mathrm{~h}$ at room temperature and then at $4^{\circ} \mathrm{C}$ overnight. After the slides had been washed in tris-buffered saline, secondary incubations were carried out with biotinylated linked secondary antibody and peroxidase-labelled streptavidin (Ultravision Quanto Detection System, Fermont, Calif., USA). Immunoreactivity was visualized using $3^{\prime}, 3^{\prime}$-diaminobenzidene peroxidase substrate for 2-3 min, counterstained with hematoxylin and examined by light microscopy. Breast carcinoma was taken as a positive control. Nuclear staining was considered positive for Sirt1 protein.

\section{Classification of Immunohistochemically Stained Patterns}

For Sirt1 analysis, tumors were scored by assessment of the proportion and intensity of the stained tumor cells. Positively stained cells were counted in 10 randomly selected fields under $\times 40$ magnification. Intensity was graded as negative $(0)$, weak $(1+)$, moderate $(2+)$ or intense $(3+)$, and the percentage of the stained cells was classified as $\leq 50 \%$ (grade 1 ), $51-75 \%$ (grade 2 ) or $>75 \%$ (grade 3). Sirt1 expression of any intensity in $>10 \%$ cells was considered positive; this was in agreement with one of our previous studies wherein we had used vascular endothelial growth factor antibody in retinoblastoma [13].

\section{Statistical Analysis}

The baseline demographic and disease-related variables were summarized using descriptive statistics. Student's t test and $\chi^{2}$ tests were used for comparing quantitative and qualitative variables in Sirt1-positive and Sirt1-negative patients. Overall survival (OS) and progression-free survival (PFS) of these patients were estimated using Kaplan-Meier survival analysis. Progression was defined as local recurrence or metastasis. Death due to any cause was defined as an event for OS analysis. The impact of Sirt1 on OS and PFS was analyzed using the log-rank test. All statistical tests were done using Stata/SE 13.0 (StataCorp LP, College Station, Tex., USA).

\section{Results}

One hundred tissue blocks were retrieved from the archived specimens. Of these, no viable tumors was identified in 6 blocks. Hence, a total of 94 samples were analyzed for Sirt1. 
Fig. 1. Expression of Sirt1 protein by immunohistochemical staining (magnification $\times 200)$. a Negative expression (0); b weak staining $(1+)$; c moderate staining $(2+)$; d intense staining (3+) in poorly differentiated retinoblastoma.
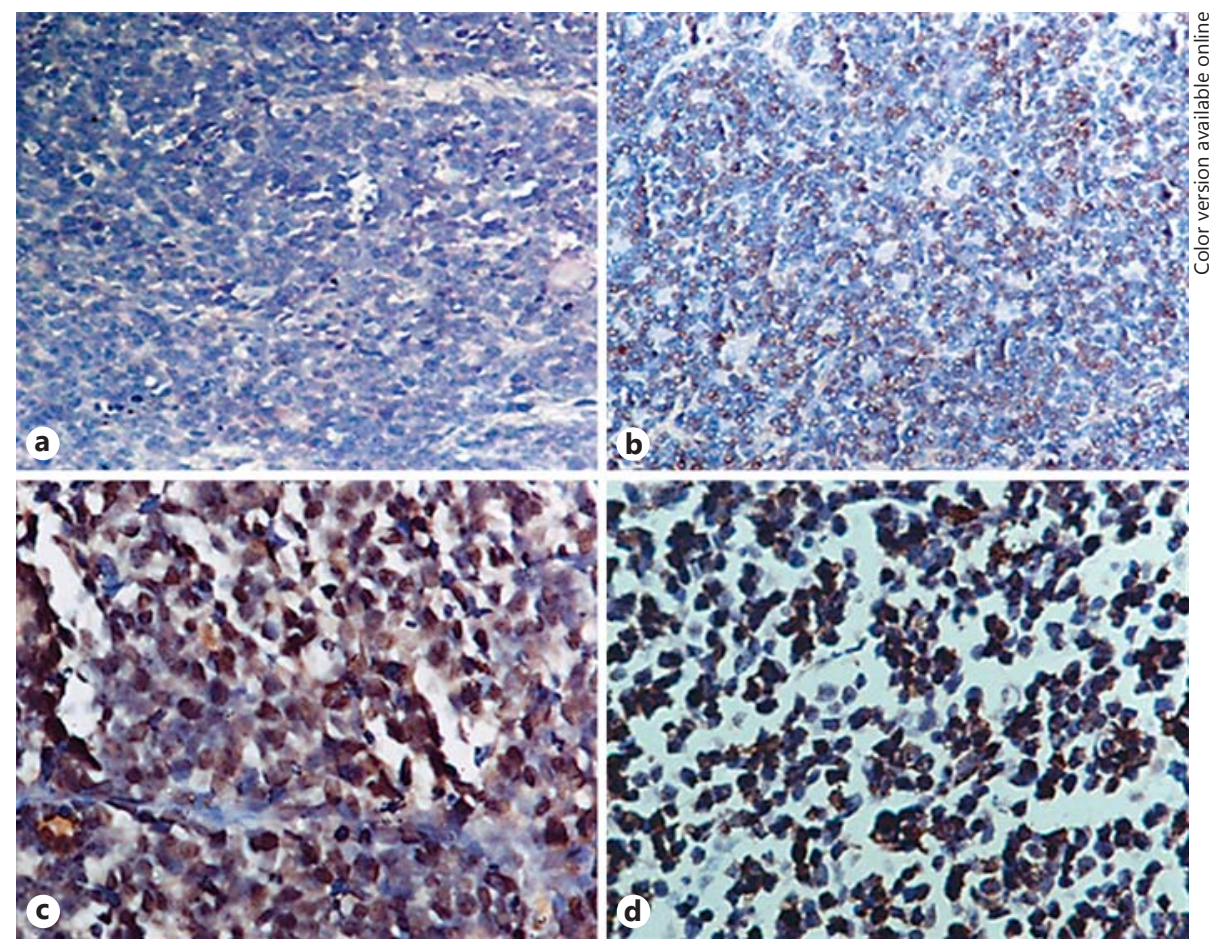

Sirt 1 was found to be positive in 89 (95\%) and negative in $5(5 \%)$ samples (fig. 1). Intense staining (3+) was observed in 50 (53\%) samples, whereas 45 (48\%) samples showed grade 3 staining (online suppl. table; see www. karger.com/doi/10.1159/000439594 for all online suppl. material). The baseline characteristics and treatment-related factors of these 94 retinoblastoma patients are shown in table 1 .

\section{Correlation with the Histopathological Features}

For comparison, expression was classified as grade 3 versus the rest. There was no difference in histopathological features between these 2 groups (table 2).

\section{Effect on Survival}

The median follow-up of this group of patients was 59 months (95\% confidence limits, 50-63). There was no effect of the degree of Sirt 1 expression (grade 3 vs. rest) on OS or PFS [5-year OS: 93\% (81-98) vs. 86\% (72-93), p = 0.23 ; 5-year PFS: $89 \%$ (75-95) vs. $88 \%$ (75-94), $\mathrm{p}=0.85$ ]. In a subgroup analysis of 46 extraocular and metastatic retinoblastoma patients, no difference was observed between the two groups [5-year OS: $94 \%(63-99)$ vs. $83 \%$ (64-93), $\mathrm{p}=0.33$; 5-year PFS: $87 \%$ (68-95) vs. 81\% (52$93), \mathrm{p}=0.66]$ (online suppl. figure).

\section{Discussion}

This study found that Sirt1 was positive in $95 \%$ of the samples. Increased Sirt1 expression has been reported previously in colon, skin, breast and prostate cancer and leukemia [14-17]. However, decreased Sirt1 mRNA expression has been reported in other studies in prostate and bladder carcinoma, glioblastoma and ovarian cancer [18]. A study elucidated that Sirt1 can deactivate retinoblastoma protein by deacetylation [8]. We hypothesize that the high frequency of Sirt 1 expression in retinoblastoma may suggest a role of Sirt1 in the pathogenesis by deacetylation and hence inactivation of retinoblastoma protein.

Sirt1 positivity was associated with a higher tumor size and TNM stage in non-small cell lung cancer and uterine cancer patients [18-20]. Contrary to this, Sirt1 expression was associated with a lower tumor stage in ovarian serous adenocarcinoma and oral squamous cell cancer [20,21]. In this study, Sirt 1 expression did not predict the stage or any high-risk histopathological features.

Likewise, Sirtl expression was associated with a shorter OS in lung cancer and diffuse large B-cell lymphoma and with prolonged OS in ovarian serous adenocarcinoma [21-23]. However, in our study, no effect of Sirt1 expression was observed either in the entire cohort or in a
88

Ocul Oncol Pathol 2016;2:86-90 DOI: $10.1159 / 000439594$
Batra/Kashyap/Singh/Bakhshi 
Table 1. Baseline and treatment-related factors of the patients

\begin{tabular}{|c|c|c|c|c|}
\hline & & $\begin{array}{l}\text { Sirt } 1 \text { <grade } 3 \\
(\mathrm{n}=49)\end{array}$ & $\begin{array}{l}\text { Sirt1 grade } 3 \\
(\mathrm{n}=45)\end{array}$ & $\mathrm{p}$ value \\
\hline \multicolumn{4}{|c|}{ Age at diagnosis, months } & 0.55 \\
\hline Median & 36 & 36 & 30 & \\
\hline Mean & $39 \pm 29$ & $41 \pm 27$ & $37 \pm 31$ & \\
\hline Range & $2-192$ & $2-144$ & $3-192$ & \\
\hline \multicolumn{4}{|l|}{ Sex } & 0.56 \\
\hline Male & $62(66)$ & $31(63)$ & $31(69)$ & \\
\hline Female & $32(34)$ & $18(37)$ & $14(31)$ & \\
\hline \multicolumn{4}{|l|}{ Disease } & 0.79 \\
\hline Unilateral & $66(70)$ & $35(71)$ & $31(69)$ & \\
\hline Bilateral & $28(30)$ & $14(29)$ & $14(31)$ & \\
\hline \multicolumn{4}{|l|}{ IRSS Stage } & 0.1 \\
\hline 1 & $48(51)$ & $19(39)$ & $29(64)$ & \\
\hline 2 & $3(3)$ & $2(4)$ & $1(2)$ & \\
\hline 3 & $38(40)$ & $25(51)$ & $13(29)$ & \\
\hline 4 & $5(5)$ & $3(6)$ & $2(4)$ & \\
\hline \multicolumn{4}{|l|}{ Surgery } & 0.61 \\
\hline Enucleation & $87(93)$ & $44(90)$ & $43(96)$ & \\
\hline Exenteration & $7(7)$ & $5(10)$ & $2(4)$ & \\
\hline \multicolumn{4}{|l|}{ Chemotherapy } & 0.61 \\
\hline No & $7(7)$ & $3(6)$ & $4(9)$ & \\
\hline Yes & 87 (93) & $46(94)$ & $41(91)$ & 0.1 \\
\hline \multicolumn{5}{|l|}{ Radiotherapy } \\
\hline No & $48(51)$ & $21(43)$ & $27(60)$ & \\
\hline Yes & $46(49)$ & $28(57)$ & $18(40)$ & \\
\hline
\end{tabular}

Values are $\mathrm{n}(\%)$, unless otherwise specified. The percentages have been rounded-off to the nearest number and hence the total may not be 100 .

limited group of extraocular and metastatic retinoblastoma.

Sirt2 and Sirt6 have recently been reported to be expressed in all 18 retinoblastoma blocks with varying intensity [24]. This study along with our study points to the functional relation between Sirt proteins and retinoblastoma and requires future functional studies.

To conclude, this study demonstrated that more than $95 \%$ of the retinoblastoma specimens expressed Sirt1. Despite this high frequency of expression, the degree of expression was not associated with any histopathological features or survival. The near uniform expression of Sirt1 in retinoblastoma specimens may suggest a pathophysiological and therapeutic role. Whether Sirt1 inhibitors will be effective in retinoblastoma needs further evaluation.
Table 2. Correlation of histopathological features with Sirtl expression

\begin{tabular}{|c|c|c|c|}
\hline & $\begin{array}{l}\text { Sirt1 <grade } 3 \\
(\mathrm{n}=49)\end{array}$ & $\begin{array}{l}\text { Sirt1 grade } 3 \\
(\mathrm{n}=45)\end{array}$ & $\mathrm{p}$ value \\
\hline Differentiation & & & 0.87 \\
\hline Good & $6(50)$ & $6(50)$ & \\
\hline Poor & $43(52)$ & $39(48)$ & \\
\hline Necrosis & & & 1 \\
\hline No & $3(60)$ & $2(40)$ & \\
\hline Yes & $46(52)$ & $43(48)$ & \\
\hline \multicolumn{3}{|c|}{ Optic nerve resected margin or postlaminar involvement } & 0.8 \\
\hline No & $36(53)$ & $32(47)$ & \\
\hline Yes & $13(50)$ & $13(50)$ & \\
\hline Choroid invasion & & & 0.29 \\
\hline No & $26(58)$ & $19(42)$ & \\
\hline Yes & $23(47)$ & $26(53)$ & \\
\hline \multicolumn{3}{|c|}{ Anterior chamber involvement } & 0.54 \\
\hline No & $39(51)$ & $38(49)$ & \\
\hline Yes & $10(59)$ & $7(41)$ & \\
\hline Iris involvement & & & 0.73 \\
\hline No & $45(53)$ & $40(47)$ & \\
\hline Yes & $4(44)$ & $5(56)$ & \\
\hline Ciliary body involvement & & & 0.77 \\
\hline No & $43(53)$ & $38(47)$ & \\
\hline Yes & $5(46)$ & $7(54)$ & \\
\hline Scleral invasion & & & 0.64 \\
\hline No & $41(53)$ & $36(47)$ & \\
\hline Yes & $8(47)$ & $9(53)$ & \\
\hline
\end{tabular}

Values are presented as $n(\%)$. The percentages have been rounded-off to the nearest number and hence the total may not be 100.

\section{Statement of Ethics}

All procedures involving human participants performed in the study were in accordance with the ethical standards of the institutional research committee and with the 1964 Helsinki Declaration and its later amendments or comparable ethical standards.

\section{Disclosure Statement}

The authors declare that they have no conflicts of interest. 


\section{References}

1 Frye RA: Phylogenetic classification of prokaryotic and eukaryotic Sir2-like proteins. Biochem Biophys Res Commun 2000;273: 793-798.

2 Brooks CL, Gu W: p53 activation: a case against Sir. Cancer Cell 2008;13:377-378.

3 Sinclair DA: Toward a unified theory of caloric restriction and longevity regulation. Mech Ageing Dev 2005;126:987-1002.

4 Brooks CL, Gu W: How does SIRT1 affect metabolism, senescence and cancer? Nat Rev Cancer 2009;9:123-128.

5 Cohen HY, Miller C, Bitterman KJ, Wall NR, Hekking B, Kessler B, Howitz KT, Gorospe M, de Cabo R, Sinclair DA: Calorie restriction promotes mammalian cell survival by inducing the SIRT1 deacetylase. Science 2004;305: 390-392.

6 Dimova DK, Dyson NJ: The E2F transcriptional network: old acquaintances with new faces. Oncogene 2005;24:2810-2826.

7 Chan HM, Krstic-Demonacos M, Smith L, Demonacos C, La Thangue NB: Acetylation control of the retinoblastoma tumour-suppressor protein. Nat Cell Biol 2001;3:667674.

8 Wong S, Weber JD: Deacetylation of the retinoblastoma tumour suppressor protein by SIRT1. Biochem J 2007;407:451-460.

9 Wang J, Kim TH, Ahn MY, Lee J, Jung JH, Choi WS, et al. Sirtinol, a class III HDAC inhibitor, induces apoptotic and autophagic cell death in MCF-7 human breast cancer cells. Int J Oncol 2012;41:1101-1109.

10 Wilking MJ, Singh CK, Nihal M, Ndiaye MA, Ahmad N: Sirtuin deacetylases: a new target for melanoma management. Cell Cycle Georget Tex 2014;13:2821-2826.
11 Bakhshi S, Gupta S, Gogia V, Ravindranath Y: Compliance in retinoblastoma. Indian J Pediatr 2010;77:535-540.

12 Radhakrishnan V, Kashyap S, Pushker N, Sharma S, Pathy S, Mohanti BK, Vishnubhatla S, Ghose S, Bakhshi S: outcome, pathology and compliance in orbital retinoblastoma (IRSS stage III) treated with neoadjuvant chemotherapy a prospective study. Ophthalmology 2012;119:1470-1477.

13 Radhakrishnan V, Kashyap S, Singh L, Pushker N, Bakhshi S: Prognostic significance of VEGF at baseline in orbital retinoblastoma (IRSS stage II and stage III). Pediatr Blood Cancer 2012;59:769-770.

14 Zhang Y, Zhang M, Dong H, Yong S, Li X, Olashaw N, Kruk PA, Cheng JQ, Bai W, Chen J, Nicosia SV, Zhang X: Deacetylation of cortactin by SIRT1 promotes cell migration. Oncogene 2009;28:445-460.

15 Huffman DM, Grizzle WE, Bamman MM, Kim JS, Eltoum IA, Elgavish A, Nagy TR: SIRT1 is significantly elevated in mouse and human prostate cancer. Cancer Res 2007;67: 6612-6618.

16 Stünkel W, Peh BK, Tan YC, Nayagam VM, Wang X, Salto-Tellez M, Ni B, Entzeroth M, Wood J: Function of the SIRT1 protein deacetylase in cancer. Biotechnol J 2007;2: 1360-1368.

17 Wang R-H, Sengupta K, Li C, Kim HS, Cao L, Xiao C, Kim S, Xu X, Zheng Y, Chilton B, Jia R, Zheng ZM, Appella E, Wang XW, Ried T, Deng CX: Impaired DNA damage response, genome instability, and tumorigenesis in SIRT1 mutant mice. Cancer Cell 2008;14: 312-323.
18 Zhang T, Rong N, Chen J, Zou C, Jing H, Zhu $\mathrm{X}$, Zhang W: SIRT1 expression is associated with the chemotherapy response and prognosis of patients with advanced NSCLC. PLoS One 2013;8:e79162.

19 Chen X, Hokka D, Maniwa Y, Ohbayashi C, Itoh T, Hayashi Y: Sirt1 is a tumor promoter in lung adenocarcinoma. Oncol Lett 2014;8: 387-393.

20 Teramae M, Fukuda T, Wada T, Kawanishi M, Imai K, Yamauchi M, Yasui T, Sumi T: Sirtuin 1 expression predicts the efficacy of neoadjuvant chemotherapy for locally advanced uterine cervical cancer. Mol Clin Oncol 2015; 3:73-78.

21 Jang KY, Kim KS, Hwang SH, Kwon KS, Kim KR, Park HS, Park BH, Chung MJ, Kang MJ, Lee DG, Moon WS: Expression and prognostic significance of SIRT1 in ovarian epithelial tumours. Pathology (Phila) 2009;41:366371

22 Chen IC, Chiang WF, Huang HH, Chen PF, Shen YY, Chiang HC: Role of SIRT1 in regulation of epithelial-to-mesenchymal transition in oral squamous cell carcinoma metastasis. Mol Cancer 2014;13:254.

23 Jang KY, Hwang SH, Kwon KS, Kim KR, Choi HN, Lee NR, Kwak JY, Park BH, Park HS, Chung MJ, Kang MJ, Lee DG, Kim HS, Shim $\mathrm{H}$, Moon WS: SIRT1 expression is associated with poor prognosis of diffuse large B-cell lymphoma. Am J Surg Pathol 2008;32:15231531.

24 Orellana ME, Quezada C, Maloney SC, Antecka E, Balazsi M, Burnier MN: Expression of SIRT2 and SIRT6 in retinoblastoma. Ophthalmic Res 2015;53:100-108. 